\title{
Research on the Mechanism Innovations of Rural Finance against the Background of Supply-side Reform
}

\author{
Chenghao Sun
}

Shandong Management University, Jinan,250357, China

Keywords: Rural finance, Mechanism innovations, Supply-side reform

\begin{abstract}
After years of development, China's rural finance has achieved remarkable results in the demand-side with the support of the multi policy system. However, there are many problems in the supply side of rural finance in china, such as the problems of single finance product, high finance risk and imperfect finance guarantee. In view of these problems, this paper puts forward some countermeasures and suggestions to provide some references for the innovation of rural financial mechanism in the context of supply-side reform.
\end{abstract}

\section{Introduction}

The rural financial supply side reform is mainly aimed at the phenomenon of China's current supply of rural financial service level is not high and the aim to solve the problem of China's rural financial market from the angle of supply, thereby enhancing the rural financial market related services, and promote the development of rural economy, increase farmers' income, increase the added value of agriculture. From a practical point of view, we must correctly grasp the necessity, connotation and innovation mechanism of the reform of the supply side of rural finance to realize the reform of the supply side of rural finance. First, to carry out the reform of agricultural supply side, we must carry out the reform of rural financial supply side. The agricultural supply side reform needs financial support, while the rural financial supply side reform can provide a broad development platform and development space for it. Secondly, the realization of agricultural modernization is bound to require the reform of the rural financial supply side. The new agricultural business entities, professional large family farms, cooperatives, rural industrialization and leading enterprise which is an important support for the modernization of agriculture, the rural financial supply side reforms must also be turned to support the new type of agricultural enterprises, increase financial support for the new agricultural business entities. Thirdly, to carry out the financial reform, we must carry out the reform of the rural financial supply side. Rural finance has always been a weak group in the whole financial system. Under the pressure of economic downturn, as a macroeconomic adjustment lever of finance, it is also urgent to supply side reform. To strengthen the rural financial supply side reform must be based on innovation, harmony, green, open and sharing for the development of the concept, this concept as a guide to improve the quality and efficiency of the supply of rural finance, to improve the supply capacity, rural financial supply, adequate supply of rural finance, rural financial development to provide financial products, product quality and financial services, to ensure the effective supply of rural finance has reasonable structure, strong protection.

\section{Mechanism Problems of Rural Finance in China}

Single Finance Product. The rural financial services products are lack of multi-level and diversity, and the service style is lack of innovation. At present, China's economy has entered a new normal, economic growth is slowing down. At the same time, the rural economic structure has been continuously optimized and upgraded, and the rural economic development has entered a new stage. Therefore, it is urgent for rural financial services products to be diversified, diversified and 
innovative. However, China's rural financial services products are single, most of the financial innovation products and services only launched in the city, the supply of rural markets is seriously inadequate, restricting the development of rural economic and social. Therefore, we should speed up the development of rural financial products and innovative services, to meet the multi-level and diversified financial demand of rural economy and society, make the farmers enjoy convenient and affordable financial services, support economic and social development in rural areas and farmers to enter a well-off society. The loan period, agriculture related financial institutions tend to term investment in two or three industries in rural areas, the traditional agricultural production loans mostly to short-term loans of less than 1 years, the rural finance loan term structure deviation not only cannot meet the needs of modern agricultural production scale of funds, and the excessive tendency of long-term loans of two or three the rural industry contains liquidity and funding policy, management risk. In addition, due to the imperfect mechanism of the government's mandatory operational subsidy mechanism and the uneven pace of economic development in different regions, it will also exacerbate the imbalance in the allocation of rural credit resources to some extent. Some local governments and financial institutions is not enough understanding of the importance of agricultural business entities to financial knowledge, enthusiasm is not high, low frequency and less time, the popularity of the effectiveness of agricultural business entities to master modern financial business knowledge, lack of capacity, hindering the further financial services in rural areas to carry out.

High Finance Risk. At present, financial institutions provide less financial products for rural economic development, and cannot provide diversified investment demand for rural areas such as securities, leasing and investment. Although the development of agricultural insurance is relatively fast, it covers a narrow range of agriculture, and farmers do not know much about insurance, so there is still a lot of room for improvement. Capital profit to commercial financial institutions prefer higher margin areas, lack of rural financial services reform and innovation of rural financial services, has the function of dislocation and loss of function of the phenomenon to a certain extent, the agricultural business entities in rural industrialization under the background of the diversified financing needs in the market as the main the operation mode of financial services is difficult to obtain effective meet. The rural financial market system is imperfect. At present, China's rural financial reform in the banking reform, the poor effectiveness of the reform policy of agricultural insurance, agricultural securities, futures and other financial aspects of agricultural products, agricultural enterprises direct financing proportion is low, the lack of a reasonable financing portfolio allocation, is not conducive to the effective management of financial enterprises, but also hinder the scale and efficiency of financing the agricultural business entities. Agriculture and agricultural production weak dispersion characteristics and lead to agriculture related products as non-fixed price and the value of collateral, high cost and high risk also determines the financial support for agriculture. In the dilemma of realizing the public welfare attribute of agriculture and meeting the creation of its own value, the financial institutions mainly based on market-oriented management model mostly choose to avoid the market risk of agriculture. Although countries take a variety of ways to make a strong guidance on financial support for agriculture, but before the modernization, market-oriented operation has not been included in the track in agricultural production, rural financial supply side reform process are still subject to the restrictions of their own characteristics of agriculture.

Imperfect Finance Gurantee. Because of the financial organization to carry out the financial literacy rate is low, narrow coverage, as well as the rural credit system, legal guarantee mechanism is not complete and other practical reasons, leading to rural financial supply and demand both sides because of the lack of decision basis and guarantee of the right and the contradiction between supply and demand. County finance organization is the vanguard of financial support for agriculture and the main implementation, but the current running state in most areas of county finance is not optimistic, mainly as follows: one is the county financial institutions due to lack of legal status, weak infrastructure and other reasons, resulting in the county financial system lack of vitality; two is under the new economic norm, superior approval of the Bank of credit and the consensual loan size control more stringent, resulting in the county financial institutions loan ratio is generally low, reducing the 
county financial credit market activity. The unbalanced development of regional economy leads to the uncoordinated development of rural finance. Rural finance is in the central position in rural economic development. Finance is born in the economy and relies on economic development, meanwhile, the economy is the basis of financial development. The stronger the regional agricultural economy is, the more encouraging it will be to the development of rural financial services, and the higher the development degree of rural financial services, the more it can promote the further development of the agricultural economy in the region. The number of institutions and personnel in rural areas and network coverage in developed areas are far higher than those in backward areas. In China's rural financial credit business practice, on the one hand, because the real information of the financial institutions to pay high costs to the main agricultural production; on the other hand, agricultural business entities and widespread financial ability is poor, the concept of financial consumption is more traditional, grasp and use of financial instruments or products, especially electronic network financial instruments or products is not strong phenomenon.

\section{Countermeasures of Mechanism Innovations of Rural Finance under the Background of Supply-side Reform}

Enrich Finance Products. According to the characteristics of rural areas, vigorously develop the financial transaction infrastructure, and innovation has special advantage industries, such as agricultural science and technology of rural tourism can be set of financial products, to increase product types, expand the business scope of financial products, to form a system of diversified rural products all the time. In the innovation of rural financial products, first, should be based on the demand of rural financial market oriented, adhere to the scientific principle of rural financial product innovation based on customer demand diversification, enhance the effective supply of rural finance. Secondly, the establishment of financial, insurance, securities, futures, trust and other industry coordination mechanisms to develop complementary and mutually integrated products. Thirdly, adhere to the principle of suiting local conditions. In the condition of underdeveloped areas, with roots in the traditional financial products, the development of Inclusive Finance as the main line, in the economically developed areas, to vigorously develop modern financial products land trust, electronic finance, network finance as the main line, to meet the diversified financial needs of agricultural management. Finally, explore the development of agricultural industry investment funds, private equity funds and policy risk funds and other new rural financial products, to a certain extent, ease the financing of agricultural production, research, marketing and other aspects of financing. In the rural financial service innovation, firstly, strengthen the rural financial network and infrastructure construction, convenience, embody the principle of efficiency; secondly, the establishment of rural financial system of personnel training, improve the efficiency of financial services in rural areas; finally, in promoting the rural credit market at the same time, accelerate the development of agricultural insurance, securities and futures markets. The establishment of complete function, division of labor, and orderly competition in the rural financial service system, promote the formation of rural financial industry collaboration to help farmers "situation and development.

Control Finance Risk. To improve the quality and efficiency of rural financial supply side reform, we should establish inclusive rural financial supervision mode, including the following: to combine risk supervision with functional supervision. On the one hand, to change the traditional emphasis on financial risk control regulation, in the protection of rural financial security at the same time, strengthen the function of supervision of financial services in rural areas, to prevent the outflow of funds in rural areas, the structure of loan object is unhealthy phenomenon, and earnestly implement the agriculture related financial institutions service requirements. Achieving regulatory differentiation. According to the characteristics of various agriculture related financial institutions, through the way of legislation of rural financial institutions will distinguish categories according to the function value, and to develop appropriate rural financial supervision system according to their respective functional requirements, to improve the pertinence and effectiveness of rural financial supervision. Establish a diversified dynamic regulatory model. Established by the people's Bank and 
Banking Regulatory Commission at all levels of unified supervision, internal supervision by the financial industry organizations, multi-level regulatory mechanism is matched with the rural financial intermediary organization, the agricultural management supervision, and promote the combination of self-supervision and external supervision, the central inspection area and cross check combination, on-site examination and review the combination of linkage of a new regulatory model is widely used. We should strengthen the risk management of nongovernmental financial activities. Can the establishment of private lending service centers in rural areas, farmers private borrowing funds both direct lending transactions provide boarding and notary and other integrated services, regulate private credit activities, to avoid the risk of private lending is reasonable. We should strengthen the construction of the rule of law environment for risk management. We should speed up the construction of the deposit insurance regulations and other financial laws and regulations. All financial institutions should strengthen their cooperation with the banking regulatory bureau, the public security and local governments, intensify the inspection of financial law enforcement, strictly crack down on illegal financial activities in rural areas, and maintain the order of rural financial markets.

Perfect Guarantee System. Establish and improve the rural credit archives and risk monitoring system. Integrity is the fundamental operation of financial services in rural health, quality directly determines the sustainable development of rural economy, the state should establish a credit system in rural areas, and rural financial institutions will be incorporated into the construction of credit system, in the daily operation, make objective and fair evaluation to the credit rating of an advantage of rural financial institutions. Gradually establish and improve the rural financial credit system. Upgrading the quality and diversity of the supply end products and meeting the multi-level demands of the society are the main tasks of the structural reform of the supply side. Therefore, rural financial institutions must comply with the needs of rural economic and social development, vigorously carry out financial services innovation, strengthen the quality of financial services supply, and improve their market competitiveness. With the expansion of business and fierce competition, financial risks are bound to increase. Therefore, the government should establish and improve the rural financial supervision system, one is the government to do monitoring pre audit and business and full supervision after security; two is that the government should implement differentiated supervision, according to the different regions and different degree of supervision of financial products should be treated differently; the three is the establishment of risk emergency system, the government should reserve for emergency funds of agricultural credit risk, there is a crisis in agricultural credit, timely assistance, though. Reasonably solve and prevent the occurrence of rural financial risks, hold the bottom line of large-scale financial risk crisis, and ensure the healthy development of rural finance.

\section{Conclusion}

Under the background of agricultural supply side structural reform, the rural financial innovation and development should be initiated from various aspects. The construction of a perfect financial organization system is the foundation, and promoting the innovation of agricultural financial service model is a breakthrough, and the realization of agricultural related financial product innovation is the key, and strengthening the supervision of rural financial risk is the guarantee. Only to improve the current situation of rural financial services, improve the level of rural financial services, in order to better meet the agricultural supply side structural reform of financial demand, promote agricultural supply side structural reform, agricultural development, rural progress of farmers' income.

\section{Acknowledgement}

This paper is the result of the subject of "Research on the Construction of Rural Social Security System in Jinan under the Background of Urban and Rural Integration".

\section{References}


[1] Dong Xiaolin, Zhu Minjie. Supply-side Structural Reform of Rural Finance and Inclusive Financial System [J]. Journal of Nanjing Agricultural University (Social Sciences Edition), 2016, 16(6): 14-18+152.

[2] Bai Pengfei, Wang Baoying. A Research on the Innovation and Development of the Rural Finance Under the Reform of the Supply-side [J]. Journal of Yanan University (Social Sciences), 2016, 38(6): 77-80.

[3] Pan Xiaojian, Du Li. Promoting the Further Development of Inclusive Finance in Rural Areas from the Supply-side Reform [J]. Economic Review, 2017(2): 17-21.

[4] Sun Tongquan. Supply-Side Structural Reform of Rural Inclusive Finance in China: An Analysis based on Farmer Households' Balance Sheet [J]. Chinese Rural Economy, 2017(5): 31-44. 